\title{
Maximizing Operations Processes of a Potential World Class University Using Mathematical Model
}

\author{
Agarana Michael ${ }^{1}$, Ayeni Foluso ${ }^{2}$ \\ ${ }^{1}$ Department of Mathematics, Covenant University Ota, Ogun State, Nigeria \\ ${ }^{2}$ Department of Computer and Information Sciences, Covenant University, Ota, Ogun State, Nigeria
}

\section{Email address:}

Michael.agarana@covenantuniversity.edu.ng (A. Michael)

\section{To cite this article:}

Agarana Michael, Ayeni Foluso. Maximizing Operations Processes of a Potential World Class University Using Mathematical Model. American Journal of Applied Mathematics. Vol. 3, No. 2, 2015, pp. 59-63. doi: 10.11648/j.ajam.20150302.15

\begin{abstract}
Many Universities are striving to attain the status of a World Class University. Some Parameters used in ranking universities include: Quality of education and teaching, Research, citation, international outlook, Alumni, Awards and Industry Outlook, operations and processes of a potential world class university should be directed optimally towards these parameters. This paper proposes a simple method of maximizing the operations processes of such universities in order to attain world class status. Operations Research techniques are employed to model the situation and solutions obtained using simplex method with the aid of computer software. It is observed that a lot of attention have to be paid to research publications, Alumni employment and international collaboration and linkages. Also the manpower should be motivated in order to become a world class university.
\end{abstract}

Keywords: World Class University, Simplex Method, Operations Research, Optimization, Linear Programming, Operations Processes

\section{Introduction}

Organizations such as universities use six categories of inputs in their operations processes, these are: Human resources, Raw materials, Capital, Time, Information and Finance. Operations Processes include inputs, transformation and outputs.[3] Operational processes and procedures ensure a standardized approach to all activities performed. No organization can afford numerous ways to accomplish activities, nor can it afford additional opportunities to induce failure from lack of defined and documented operational process and procedures.[4]. Operating processes produce and deliver goods and services to customers, and while operational excellence alone is not the basis of a sustainable strategy, managing operations remains a priority for all organizations. Without excellent operations, companies will find it difficult to execute strategies.[6] For a university to be the one of the best in the world, such a university should maximize her operations processes, especially the input, because if the inputs are not good, the output are meant to be bad. Students can regarded as output of a university operations processes. They are the most valuable assets of a world-class university, and the quality of such universities is determined by the academic performance of students in such institutions.[2,7] Also, among world class universities' most significant resources is there talented and highly respected faculty. Many faculty members are recognized for their exceptional scholarship. [8] The Mathematical model used in this paper is Linear Programming model. Linear Programming is a branch of Mathematics that deals with solving optimization problems. It consists of linear function to be minimized or maximized subject to certain constraints [4]. Among its significance are that it's a widely applicable problem solving model and ranked among the most scientific advances of the 20th century. It has been applied in areas like management, economics, operations research, computer science, and more. [1,2]. The inputs of the operations processes are maximized using linear programming method in order to turn out optimal outputs.

\section{Formulation of Problem}

\subsection{Components of Linear Programming}

\subsubsection{The Objective}

The objective of this paper is to maximize the operations process of a potential University that will enhance their 
chances of being a world class university.

\subsubsection{The Activities (Decision Variables)}

- Quality of education and teaching

- Research

- Citation(Research Influence)

- International Outlook

- Alumni(Involvement of Alumni)

- Awards(received from reputable bodies)

- Industry Income(from university products)

\subsubsection{Constraints}

The resources needed to carry out the above activities successfully are labour, material, machine, money. These resources are limited in supply. A potential University is expected to maximize her operation processes, through the inputs or resources towards satisfying the ranking requirement by the ranking agencies. The inputs to the operations processes are in six categories namely: Human Resources, Raw materials/components, capital (with plant and equipment), time (critical non-reversible resource), information, knowledge and finance. These resources (inputs) needed to carry out the above activities are limited in supply. For the purpose of this paper, we adopt the following as the available quantity of these resources for a year:

Table 1. Resources available for a year.

\begin{tabular}{ll}
\hline Resources & Available Quantity for a year \\
\hline Human Resources & 80 million hrs \\
Raw Materials & 50 million units \\
Capital(plants/equipment) & 900 million Naira \\
Time & 100 million hrs \\
Information & 10 million \\
Finance & 500 million \\
\hline
\end{tabular}

\subsubsection{Contribution}

From the data considered, the contributions of the resources to the activities, in percentage form, are as follows respectively.

$$
\begin{gathered}
\mathrm{C}_{1}=50 \%, \mathrm{C}_{2}=90 \%, \mathrm{C}_{3}=80 \%, \mathrm{C}_{4}=50 \%, \mathrm{C}_{5}=50 \%, \mathrm{C}_{6}=70 \%, \\
\mathrm{C}_{7}=60 \%
\end{gathered}
$$

\subsection{Mathematical Representation}

In line with the assumptions of Linear Programming, we represent in quantitative form, the objective function, decision variables, constraints and contributions:

The activities are our decision variable represented as follows:

$\mathrm{x}_{1}$ represents quality of education measured by the number of high ratings on quality received.

$\mathrm{x}_{2}$ represents number of research works.

$\mathrm{x}_{3}$ represents number of citations.

$\mathrm{x}_{4}$ represents international outlooks measured by a number of international students and staff.

$\mathrm{x}_{5}$ represents alumni, measured by number of seconds worked by all the Alumni employed.

$\mathrm{x}_{6}$ represents awards measured by number of awards received since inception. $\mathrm{x}_{7}$ represents industrial outlook measured by number of the university products useful for the industry.

The contributions are as follows: $\mathrm{C}_{1}=50, \mathrm{C}_{2}=90, \mathrm{C}_{3}=80$ $\mathrm{C}_{4}=50 \mathrm{C}_{5}=50, \mathrm{C}_{6}=70, \mathrm{C} 7=60$

The Objective function becomes:

$$
Z=\sum_{i=1}^{7} C_{i} X_{i}
$$

That is, $\mathrm{Z}=\mathrm{C}_{1} \mathrm{X}_{1}+\mathrm{C}_{2} \mathrm{X}_{2}+\mathrm{C}_{3} \mathrm{X}_{3}+\mathrm{C}_{4} \mathrm{X}_{4}+\mathrm{C}_{5} \mathrm{X}_{5}+\mathrm{C}_{6} \mathrm{X}_{\mathrm{i6}}+$ $\mathrm{C}_{7} \mathrm{X}_{7}=50 \mathrm{x}_{1}+90 \mathrm{x}_{2}+80 \mathrm{x}_{3}+50 \mathrm{x}_{4}+50 \mathrm{x}_{5}+70 \mathrm{x}_{6}+60 \mathrm{x}_{7}$

Let $a_{i j}$ be the quantity of resource $i$ per unit of activity $j$, represented as follows:

\subsubsection{Labour Hours per Unit of Activity}

$\mathrm{a}_{11}=$ Labour hour for activity 1

$a_{12}=$ Labour hour for activity 2

$a_{13}=$ Labour hour for activity 3

$\mathrm{a}_{14}=$ Labour hour for activity 4

$\mathrm{a}_{15}=$ Labour hour for activity 5

$\mathrm{a}_{16}=$ Labour hour for activity 6

$\mathrm{a}_{17}=$ Labour hour for activity 7

\subsubsection{Quantity of Material per Unit of Activity}

$\mathrm{a}_{21}=$ Quantity of material for activity 1

$\mathrm{a}_{22}=$ Quantity of material for activity 2

$\mathrm{a}_{23}=$ Quantity of material for activity 3

$\mathrm{a}_{24}=$ Quantity of material for activity 4

$\mathrm{a}_{25}=$ Quantity of material for activity 5

$\mathrm{a}_{26}=$ Quantity of material for activity 1

$\mathrm{a}_{27}=$ Quantity of material for activity 1

\subsubsection{Amount of Capital per Unit of Activity}

$\mathrm{a}_{31}=$ Amount of capital needed for activity 1 $a_{32}=$ Amount of capital needed for activity 2 $a_{33}=$ Amount of capital needed for activity 3 $\mathrm{a}_{34}=$ Amount of capital needed for activity 4 $\mathrm{a}_{35}=$ Amount of capital needed for activity 5 $\mathrm{a}_{36}=$ Amount of capital needed for activity 6 $a_{37}=$ Amount of capital needed for activity 7

\subsubsection{Number of Hours per Unit of Activity} $\mathrm{a}_{41}=$ Number of hours needed for activity 1 $a_{42}=$ Number of hours needed for activity 2 $a_{43}=$ Number of hours needed for activity 3 $a_{44}=$ Number of hours needed for activity 4 $a_{45}=$ Number of hours needed for activity 5 $\mathrm{a}_{46}=$ Number of hours needed for activity 6 $a_{47}=$ Number of hours needed for activity 7

\subsubsection{Level of Information per Unit of Activity} $\mathrm{a}_{51}=$ Level of information needed for activity 1 $a_{52}=$ Level of information needed for activity 2 $a_{53}=$ Level of information needed for activity 3 $a_{54}=$ Level of information needed for activity 4 $a_{55}=$ Level of information needed for activity 5 $a_{56}=$ Level of information needed for activity 6 $a_{57}=$ Level of information needed for activity 7 


\subsubsection{Level of Information per Unit of Activity}

$\mathrm{a}_{61}=$ Level of finance needed for activity 1 $\mathrm{a}_{62}=$ Level of finance needed for activity 2 $a_{63}=$ Level of finance needed for activity 3 $\mathrm{a}_{64}=$ Level of finance needed for activity 4 $\mathrm{a}_{65}=$ Level of finance needed for activity 5 $a_{66}=$ Level of finance needed for activity 6 $\mathrm{a}_{67}=$ Level of finance needed for activity 7 The Constraints are as follows:

$$
\sum_{\mathrm{i}=1}^{6} \sum_{\mathrm{j}=1}^{7} \mathrm{a}_{\mathrm{ij}} \mathrm{x}_{\mathrm{ij}} \leq \mathrm{b}_{\mathrm{i}},
$$

where $b_{i}$ are the available resources.

That is,

$$
\begin{aligned}
& a_{11} x_{1}+a_{12} x_{2}+a_{13} x_{3}+a_{14} x_{4}+a_{15} x_{5}+a_{16} x_{6}+a_{17} x_{7} \leq b_{1} \\
& a_{21} x_{1}+a_{22} x_{2}+a_{23} x_{3}+a_{24} x_{4}+a_{25} x_{5}+a_{26} x_{6}+a_{27} x_{7} \leq b_{2} \\
& a_{31} x_{1}+a_{32} x_{2}+a_{33} x_{3}+a_{34} x_{4}+a_{35} x_{5}+a_{36} x_{6}+a_{37} x_{7} \leq b_{3} \\
& a_{41} x_{1}+a_{42} x_{2}+a_{43} x_{3}+a_{44} x_{4}+a_{45} x_{5}+a_{46} x_{6}+a_{47} x_{7} \leq b_{4} \\
& a_{51} x_{1}+a_{52} x_{2}+a_{53} x_{3}+a_{54} x_{4}+a_{55} x_{5}+a_{56} x_{6}+a_{57} x_{7} \leq b_{5} \\
& a_{61} x_{1}+a_{62} x_{2}+a_{63} x_{3}+a_{64} x_{4}+a_{65} x_{5}+a_{66} x_{6}+a_{67} x_{7} \leq b_{6} \\
& x_{i} \geq 0 ; i=1,2, \ldots, 7 \\
& \text { From the data gathered, the values of } a_{i j} \text { are as follows: } \\
& a_{11}=10, a_{12}=20, a_{13}=0, a_{14}=2, a_{15}=0, a_{16}=0, a_{17}=15 \\
& a_{21}=50, a_{22}=80, a_{23}=0, a_{24}=0, a_{25}=0, a_{26}=0, a_{27}=0 \\
& a_{31}=5, a_{32}=50, a_{33}=0, a_{34}=2, a_{35}=10, a_{36}=0, a_{37}=0 \\
& a_{41}=12, a_{42}=35, a_{43}=30, a_{44}=80, a_{45}=0, a_{46}=50, a_{47}= \\
& 0 \\
& a_{51}=10, a_{52}=70, a_{53}=20, a_{54}=10, a_{55}=0, a_{56}=2, a_{57}=5 \\
& a_{61}=10, a_{62}=30, a_{63}=0, a_{64}=0, a_{65}=0, a_{66}=0, a_{67}=10
\end{aligned}
$$$$
90
$$

\section{The Model}

Maximize $Z=50 X_{1}+90 X_{2}+80 X_{3}+50 X_{4}+50 X_{5}+70 X_{6}+$

\begin{tabular}{|c|c|c|c|c|c|c|c|c|c|c|c|c|c|c|}
\hline Solution Variable & $X_{1}$ & $\mathbf{X}_{2}$ & $\mathbf{X}_{3}$ & $\mathbf{X}_{4}$ & $\mathbf{X}_{5}$ & $\mathbf{X}_{6}$ & $\mathbf{X}_{7}$ & $\mathbf{X}_{8}$ & $\mathbf{X}_{9}$ & $\mathbf{X}_{10}$ & $\mathbf{X}_{11}$ & $\mathbf{X}_{12}$ & $\mathbf{X}_{13}$ & Solution Quantity \\
\hline $\mathrm{X}_{8}$ & 10 & 20 & 0 & 2 & 0 & 0 & 15 & 1 & 0 & 0 & 0 & 0 & 0 & $80,000,000$ \\
\hline $\mathrm{X}_{9}$ & 50 & 80 & 0 & 0 & 0 & 0 & 0 & 0 & 1 & 0 & 0 & 0 & 0 & $50,000,000$ \\
\hline $\mathrm{X}_{10}$ & 5 & 50 & 0 & 2 & 10 & 0 & 0 & 0 & 0 & 1 & 0 & 0 & 0 & $900,000,000$ \\
\hline $\mathrm{X}_{11}$ & 12 & 35 & 30 & 80 & 0 & 50 & 90 & 0 & 0 & 0 & 1 & 0 & 0 & $100,000,000$ \\
\hline $\mathrm{X}_{12}$ & 10 & 70 & 20 & 10 & 0 & 2 & 5 & 0 & 0 & 0 & 0 & 1 & 0 & $10,000,000$ \\
\hline $\mathrm{X}_{13}$ & 10 & 30 & 0 & 0 & 0 & 0 & 10 & 0 & 0 & 0 & 0 & 0 & 1 & $500,000,000$ \\
\hline Z & 50 & 90 & 80 & 50 & 50 & 70 & 60 & 0 & 0 & 0 & 0 & 0 & 0 & \\
\hline
\end{tabular}

$60 \mathrm{X}_{7}$

Subject to:

$$
\begin{aligned}
& 10 X_{1}+20 X_{2}+2 X_{4}+15 X_{7} \leq 80,000,000 \\
& 50 X_{1}+80 X_{2} \leq 50,000,000 \\
& 5 X_{1}+50 X_{2}+2 X_{4}+10 X_{5} \leq 900,000,000 \\
& 12 X_{1}+35 X_{2}+30 X_{3}+80 X_{4}+50 X_{6}+90 X_{7} \leq 100,000,000 \\
& 10 X_{1}+70 X_{2}+20 X_{3}+10 X_{4}+2 X_{6}+5 X_{7} \leq 10,000,000 \\
& 10 X_{1}+30 X_{2}+10 X_{7} \leq 500,000,000 \\
& X i \geq 0, i=1,2,3, \ldots, 7
\end{aligned}
$$

\section{Model Solution}

We employ simplex method to the Standardized form of the above model by presenting the initial simplex tableau.

\subsection{Standardized Model}

Maximize $Z=50 X_{1}+90 X_{2}+80 X_{3}+50 X_{4}+50 X_{5}+70 X_{6}+$ $60 \mathrm{X}_{7}$

\section{Subject to:}

$$
\begin{aligned}
& 10 \mathrm{X}_{1}+20 \mathrm{X}_{2}+2 \mathrm{X}_{4}+15 \mathrm{X}_{7}+\mathrm{X}_{8}=80,000,000 \\
& 50 \mathrm{X}_{1}+80 \mathrm{X}_{2}+\mathrm{X}_{9}=50,000,000 \\
& 5 \mathrm{X}_{1}+50 \mathrm{X}_{2}+2 \mathrm{X}_{4}+10 \mathrm{X}_{5}+\mathrm{X}_{10}=900,000,000 \\
& 12 \mathrm{X}_{1}+35 \mathrm{X}_{2}+30 \mathrm{X}_{3}+80 \mathrm{X}_{4}+50 \mathrm{X}_{6}+90 \mathrm{X}_{7}+\mathrm{X}_{11}= \\
& 100,000,000 \\
& 10 \mathrm{X}_{1}+70 \mathrm{X}_{2}+20 \mathrm{X}_{3}+10 \mathrm{X}_{4}+2 \mathrm{X}_{6}+5 \mathrm{X}_{7}+\mathrm{X}_{12}=10,000,000 \\
& 10 \mathrm{X}_{1}+30 \mathrm{X}_{2}+10 \mathrm{X}_{7}+\mathrm{X}_{13}=500,000,000 \\
& \mathrm{Xi} \geq 0, \mathrm{i}=1,23, \ldots, 7
\end{aligned}
$$

where $X_{8}, X_{9}, X_{10}, X_{11}, X_{12}$, and $X_{13}$ are slack variables .

\subsection{Initial Simplex Tableau}

Table 2. Initial Simplex Tableau.

\section{Result Discussion}

In this study, seven decision variables $\left(\mathrm{X}_{1}, \mathrm{X}_{2}, \ldots, \mathrm{X}_{7}\right)$ were considered, which represent the amount or volume of activities of a potential world class university. Other variables are also considered. In all, twelve variables and six constraints, excluding the non-negativity constraint, are involved. A computer package is employed in solving the problem. After running the program on computer, the following results were obtained; variables $\mathrm{X}_{3}=319149, \mathrm{X}_{5}=$ $9 \mathrm{e}+007$ and $\mathrm{X}_{6}=1.80851 \mathrm{e}+006$ while other decision variables have zero value. This implies that the number of citations expected within the specified period should not be less than 319149, while the period of time all the alumni involved in one activity or the other in the system should at least be 90,000,000 Seconds. The number of awards received, since inception, should be up to 180,8510 .

\section{Conclusion}

This work deals with maximization of a potential University operations processes. A Mathematical modelling approach was adopted and simplex method of solution was used to solve the resulting standardised model with the aid of a computer software- linear programming solver. It was observed from the result obtained that in order for a potential world class university to really become a world class university, all the inputs: Human resources, Raw materials, Capital, Time, Information and Finance must be at optimal level. Specifically, there must be a robust research activities, 
by both the students and faculty members, which would lead to many citations. The material resources required to do good research should be available. A lot of time must be spent the alumni in the activities of the university. The performance of the university compared to her equals should be outstanding. This should reflect in the number of awards won by the university. Also, the employees, both academic and non- academic, of the potential world class university should be highly motivated, in order to carry out their duties effectively and efficiently, because this will usually reflect in the overall performance of the university.

\section{Appendices}

\begin{tabular}{|c|c|c|c|c|c|c|c|c|c|c|c|c|c|c|}
\hline Basis & $\mathrm{X} 1$ & $\mathrm{X} 2$ & X3 & $\mathrm{X4}$ & X5 & X6 & $\mathbf{X 7}$ & X8 & X9 & $\mathrm{X} 10$ & X11 & $\mathrm{X} 12$ & $\mathrm{X} 13$ & RHS \\
\hline X8 & 10 & 20 & 0 & 2 & 0 & 0 & 15 & 1 & 0 & 0 & 0 & 0 & 0 & $8 \mathrm{e}+007$ \\
\hline X9 & 50 & 80 & 0 & 0 & 0 & 0 & 0 & 0 & 1 & 0 & 0 & 0 & 0 & $5 e+007$ \\
\hline X5 & 0.5 & 5 & 0 & 0.2 & 1 & 0 & 0 & 0 & 0 & 0.1 & 0 & 0 & 0 & $9 e+007$ \\
\hline X11 & 12 & 35 & 30 & 80 & 0 & 50 & 90 & 0 & 0 & 0 & 1 & 0 & 0 & $1 \mathrm{e}+008$ \\
\hline $\mathrm{X} 12$ & 10 & 70 & 20 & 10 & 0 & 2 & 5 & 0 & 0 & 0 & 0 & 1 & 0 & $1 \mathrm{e}+007$ \\
\hline X13 & 10 & 30 & 0 & 0 & 0 & 0 & 10 & 0 & 0 & 0 & 0 & 0 & 1 & $5 e+008$ \\
\hline Obj. & 25 & -160 & 80 & 40 & 0 & 70 & 60 & 0 & 0 & -5 & 0 & 0 & 0 & $1 / 0$ \\
\hline
\end{tabular}

Variable to be made basic $->\mathrm{X} 3$

Ratios: RHS/Column X3 -> \{ - - 3.33333e+006 500000 - $\}$

Variable out of the basic set $->$ X12

*** Phase II --- Iteration 1 ***

\begin{tabular}{|c|c|c|c|c|c|c|c|c|c|c|c|c|c|c|}
\hline Basis & X1 & $\mathrm{X} 2$ & X3 & X4 & X5 & X6 & $\mathbf{X 7}$ & X8 & X9 & $\mathrm{X} 10$ & X11 & $\mathrm{X} 12$ & X13 & RHS \\
\hline $\mathrm{X} 8$ & 10 & 20 & 0 & 2 & 0 & 0 & 15 & 1 & 0 & 0 & 0 & 0 & 0 & $8 e+007$ \\
\hline X9 & 50 & 80 & 0 & 0 & 0 & 0 & 0 & 0 & 1 & 0 & 0 & 0 & 0 & $5 e+007$ \\
\hline X5 & 0.5 & 5 & 0 & 0.2 & 1 & 0 & 0 & 0 & 0 & 0.1 & 0 & 0 & 0 & $9 e+007$ \\
\hline $\mathrm{X} 3$ & 0.5 & 3.5 & 1 & 0.5 & 0 & 0.1 & 0.25 & 0 & 0 & 0 & 0 & 0.05 & 0 & 500000 \\
\hline X13 & 10 & 30 & 0 & 0 & 0 & 0 & 10 & 0 & 0 & 0 & 0 & 0 & 1 & $5 e+008$ \\
\hline Obj. & -15 & -440 & 0 & 0 & 0 & 62 & 40 & 0 & 0 & -5 & 0 & -4 & 0 & $1 / 0$ \\
\hline
\end{tabular}

Variable to be made basic -> X6

Ratios: RHS/Column X6 -> \{ - - 1.80851e+006 5e+006 - $\}$

Variable out of the basic set $->$ X11

*** Phase II --- Iteration $2 * * *$

\begin{tabular}{|c|c|c|c|c|c|c|c|c|c|c|c|c|c|c|}
\hline Basis & X1 & $\mathbf{X} 2$ & $\mathbf{X 3}$ & $\mathrm{X} 4$ & X5 & X6 & $\mathbf{X} 7$ & X8 & X9 & $\mathbf{X 1 0}$ & X11 & $\mathrm{X} 12$ & $\mathrm{X13}$ & RHS \\
\hline $\mathrm{X} 8$ & 10 & 20 & 0 & 2 & 0 & 0 & 15 & 1 & 0 & 0 & 0 & 0 & 0 & $8 \mathrm{e}+007$ \\
\hline X9 & 50 & 80 & 0 & 0 & 0 & 0 & 0 & 0 & 1 & 0 & 0 & 0 & 0 & $5 e+007$ \\
\hline $\mathrm{X} 5$ & 0.5 & 5 & 0 & 0.2 & 1 & 0 & 0 & 0 & 0 & 0.1 & 0 & 0 & 0 & $9 e+007$ \\
\hline $\mathrm{X} 3$ & $119 / 235$ & $343 / 94$ & 1 & $17 / 47$ & 0 & 0 & $7 / 94$ & 0 & 0 & 0 & $-1 / 470$ & $5 / 94$ & 0 & 319149 \\
\hline X13 & 10 & 30 & 0 & 0 & 0 & 0 & 10 & 0 & 0 & 0 & 0 & 0 & 1 & $5 e+008$ \\
\hline Obj. & $-519 / 47$ & -347.66 & 0 & $-4030 / 47$ & 0 & 0 & $-3235 / 47$ & 0 & 0 & -5 & $-62 / 47$ & $-95 / 47$ & 0 & $1 / 0$ \\
\hline
\end{tabular}

$>$ Optimal solution FOUND

$>$ Maximum $=1 / 0$

*** RESULTS - VARIABLES ***

\begin{tabular}{llll}
\hline Variable & Value & Obj. Cost & Reduced Cost \\
\hline X1 & 0 & 50 & $519 / 47$ \\
X2 & 0 & 90 & 347.66 \\
X3 & 319149 & 80 & 0 \\
X4 & 0 & 50 & $4030 / 47$ \\
X5 & $9 \mathrm{e}+007$ & 50 & 0 \\
X6 & $1.80851 \mathrm{e}+006$ & 70 & 0 \\
X7 & 0 & 60 & $3235 / 47$ \\
X8 & $8 \mathrm{e}+007$ & 0 & 0 \\
X9 & $5 \mathrm{e}+007$ & 0 & 0 \\
X10 & 0 & 0 & 5 \\
X11 & 0 & 0 & $62 / 47$ \\
X12 & 0 & 0 & $95 / 47$ \\
X13 & $5 \mathrm{e}+008$ & 0 & 0 \\
\hline
\end{tabular}


*** RESULTS - CONSTRAINTS ***

\begin{tabular}{llll}
\hline Constraint & Value & RHS & Dual Price \\
\hline Row1 & $8 \mathrm{e}+007$ & $8 \mathrm{e}+007$ & 0 \\
Row2 & $5 \mathrm{e}+007$ & $5 \mathrm{e}+007$ & 0 \\
Row3 & $9 \mathrm{e}+008$ & $9 \mathrm{e}+008$ & 5 \\
Row4 & $1 \mathrm{e}+008$ & $1 \mathrm{e}+008$ & $62 / 47$ \\
Row5 & $1 \mathrm{e}+007$ & $1 \mathrm{e}+007$ & $95 / 47$ \\
Row6 & $5 \mathrm{e}+008$ & $5 \mathrm{e}+008$ & 0 \\
\hline
\end{tabular}

\section{References}

[1] Agarana M.C., Anake T.A. and Adeleke O.J., Application of Linear Programming model to unsecured loans and bad debt risk control in banks, International journal of management , Information Technology and Engineering, 2(7), 2014, Pp 93102.

[2] M.C. Agarana and A.I. Ehigbochie, optimization of students academic performance in a world-class university using operational research technique, International journal of Mathematics and Computer Application research, 5(1), 2015, 43-50.

[3] Mary Ann Anderson, Edward Anderson and Geoffrey Parker, How to manage Operations Processes, Operations Management for Dummies. www.dummies.com

[4] Erica Olsen, Strategic Planning kit for Dummies. $2^{\text {nd }}$ Edition.
[5] Musah Sulemana, Abdul- Rahaman Haadi, Modelling the problem of profit optimization of bank X Tamale, as linear programming problem, Applied Mathematics, 4(1), 2014, Pp 22-40.

[6] Robert S. Kaplan and Davd P. Norton, Operations Management Processes, Harvard Business Review, 2003

[7] Bianka Siwinska, Rise of the world-class university, University world news, 2013, issue no: 297

[8] University of Illinois at urbana-champaign, Aworld-class university, University of Illinois board of trustees, 2015.

[9] William cook home page, Mathematical programming society and Springer verlag initial volume:2009

[10] Dantzig, G.B., Maximization of a linear function subject to linear inequalities, in T.C. Koopmans (ed), Activity Analysis of production and allocation, John Wiley and sons, New York, 1951, pp 339-347. 